\title{
Jurassic Ammonites From Southern Alaska
}

GE O L O G I A L S U R VEY PR OFESS I O A L PAPER 418

This volume was published

as separate chapters $A, B$

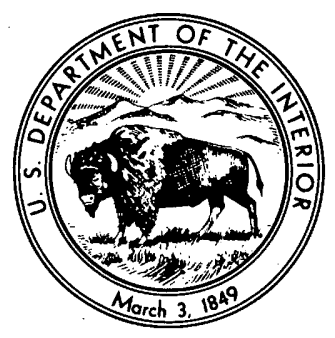

$$
\begin{aligned}
& \text { BUREAU OF, MINES } \\
& \text { LIBRARY } \\
& \text { SPOKANE, WASH. } \\
& \text { MAR } 8 \quad 1973 \\
& \text { PLEASE RETURN } \\
& \text { TO LIBRARY }
\end{aligned}
$$




\section{UNITED STATES DEPARTMENT OF THE INTERIOR}

ROGERS C. B. MORTON, Secretary

GEOLOGICAL SURVEY

V. E. McKelvey, Director 


\section{CONTENTS}

[Letters designate the separately published chapters]

(A) Late Bajocian ammonites from the Cook Inlet region, Alaska, by Ralph w. Imlay.

(B) Middle Bajocian ammonites from the Cook Inlet region, Alaska, by Ralph W. Imlay. 